\title{
Analysis of Conflicts in Serve for China: Through the Lens of Social Acceleration Theory
}

\begin{abstract}
Shuhui Pan
Graduate School of Global Studies, Doshisha University

*Corresponding author. Email: shuhui.pan@icloud.com

ABSTRACT

A dynamic and critical reflection on social entrepreneurship and social enterprise could enhance the understanding of the contradictions that are inherent to this field. We use Hartmut Rosa's critical theory of social acceleration to analyze the internal conflicts of an elite non-profit organization, Serve for China (SFC), which is focused on poverty alleviation in China. The analysis considers three perspectives: motivation for joining the SFC, the SFC model and criticism against it, and the consequences of alienation in an "acceleration society." This study highlights that social enterprises easily overlook humanistic entrepreneurship (a condition for creating harmonious resonance), philanthropic methods (a type of deceleration in reaction to acceleration), and their potential functions in the acceleration society.
\end{abstract}

Keywords: social entrepreneurship, organizational behaviors, social acceleration, alienation

\section{INTRODUCTION}

An article called "Seven Questions for Qin Yuefei" (hereafter referred to as "Seven Questions") that was posted online on August 18, 2018, drew a lot of attention and spread rapidly, especially in the field of public welfare, and gathered over 100,000 views. The article sternly questioned Qin Yuefei, the founder of Serve for China (SFC) - a Chinese non-profit organization dedicated to poverty alleviation in rural areas - regarding his integrity, and the development strategies and financial transparency of the organization.

Founded in 2016, SFC committed itself to addressing poverty alleviation through rural entrepreneurship and social innovation. Annually, a highly selected group of top Chinese graduates receive a two-year fellowship training award and are posted to poor Chinese villages. The founder and young graduates from world-renowned universities, including Yale, Harvard, UCLA, and Cambridge, lent a lot of prestige to the organization. Additionally, media reports indicated that these individuals sacrificed good salaries in big cities for public welfare in poor rural areas.

From 2016 to 2018, 58 fellows in teams of two or three were assigned to 25 villages in a Hunan Province county to conduct rural entrepreneurial projects. Beforehand, they received intensive week-long preparational training in Beijing and conducted research over a onemonth period to understand the local industry conditions and villagers' needs. Following their training, each team had to submit a business proposal which mostly involved establishing specialized cooperatives between the farmers and locals to relieve poverty through entrepreneurship. By the end of 2017, 12 agricultural cooperatives were established, including 6 major industries: crop farming, livestock breeding, agricultural product processing, rural tourism, handicrafts, and a training program for local youth (social service). The fellows received income via SFC subsidies, but no salaries or dividends were provided from the cooperatives. In turn, the SFC derived its income from personal donations and foundation funding.

The organization was different from other non-profit organizations and marked several achievements within one year. For example, SFC data indicated that, as of August 2017, one third of its fellows either had a master's degree, had studied abroad, or had over one year of working experience. In terms of return on investment, the fellows who served in villages for one year accumulated over 100,000 hours of service. Furthermore, they created 154,643 USD in revenue for the villagers through the development of local industries and introduced 1,237,145 USD in investment for the villages. Subsequently, the SFC became a public welfare phenomenon in China and accumulated approximately 1,780,616 USD from fundraising in 2017. However, in August 2018, a former fellow posed some serious questions to the organization and its star founder online. 


\section{BACKGROUND: CONFLICTS WITHIN THE SFC}

First, it is important to determine what caused the questions. During the preliminary research, set-up, and operating of cooperatives, many fellows found it very challenging to communicate effectively with the villagers. They also became aware of their insufficient management knowledge and lack of money to implement the projects. However, they hoped in vain that the SFC would provide the relevant management knowledge, skills training, or match them with entrepreneurial mentors as promised. Consequently, they had to rely on their own creative efforts to complete the required tasks within the strict deadlines. Particularly, when the cooperatives were unable to purchase production equipment, some fellows approached their families for funding to ensure timely production. Others could not secure sales channels, and asked their families and friends to purchase the products. Furthermore, the one-month preliminary research period was insufficient for some fellows to fully comprehend the local situation. They ended up relying on their own resources to take orders beyond the cooperative's capacity. Additionally, the SFC's institutional reform in April 2018 further intensified the potential conflict situation with the fellows and aggravated their frustration.

The reform involved an evaluation of existing entrepreneurial projects based on the fellows' business performance (that is, whether they empowered poor villagers to sustainably generate an income) and elimination of the other projects. Fellows presented their projects on a roadshow judged by six senior managers from investment institutions. The SFC indicated that the successful projects would receive financial and other business resources from investment institutions. However, this was met with outrage and confusion from many fellows who questioned the organization's commitment to its original social improvement intentions. Following this apparent change in vision that now reflected a commercial focus, some fellows decided to quit as they felt it violated their original intent to join, and were pessimistic about the performance and prospects of their own projects. Before the roadshow took place in May 2018, 16 fellows had announced their withdrawal. As for the fellows who participated in the roadshow, 11 projects ( 24 fellows) failed, and only 2 (6 fellows) passed.

Regarding organizational set-up, the SFC originally set up its organization structure to reflect those in the front line (the fellows in the village) and back office (the staff in the Beijing headquarter which comprised four main departments: fundraising, recruitment, marketing, and finance). However, the fellows claimed that the "back office" had become their managers, rather than partners, as originally indicated.
In "Seven Questions," the author listed the tasks that the back-office staff assigned to fellows, such as accepting media interviews and arranging visits for government officials, investors, and academic teams. These tasks occupied their time and energy, which made it difficult for them to devote themselves to local entrepreneurial projects. Moreover, the fellow stated that the projects did not bring about real change in the villages since the product/service models or innovations were not sustainable. Furthermore, recruiting and training local talent in the villages required time and patience, and therefore the fellows were unable to obtain good results within the relatively short period of services. Some fellows proposed the introduction of a social service department to cooperate with a local vocational and technical college in setting up courses that specialize in skills and management training. However, the SFC declared that they were dedicated to industrial poverty alleviation and such an education-focused initiative may blur the original focus. Subsequently, the social service department was never brought to life.

Another area of concern was the SFC's commitment toward the training of fellows. At the beginning of the fellowship program, the SFC indicated that the two main focus areas of the organization were industrial poverty alleviation and helping young people grow through experience. However, after the program had been in operation for a year, the management team explained during meetings that industrial poverty alleviation was the program's only focus. Young people (fellows) were key in reducing poverty through rural entrepreneurship, but they were not considered beneficiaries. Gradually they started feeling that they were being taken advantage of. Eventually, this prompted an intense sense of alienation within the organization and evolved into antagonism when the SFC introduced a full-on market-oriented business-like competition to reform the fellows' projects.

\section{PROBLEM STATEMENT}

Researchers have widely agreed that social entrepreneurship tends to combine social missions with entrepreneurial activities [1] [2]. Moreover, scholars have been discussing such social missions. As described by Dees [3], the social innovation schools view social entrepreneurs as innovators who promote large-scale, sustainable, and systematic social change through social enterprises. These entities are not limited to profit- or non-profit organizations. However, the social enterprise schools of Boschee and McClurg [4] argue that innovation is important in social entrepreneurship. Therefore, social enterprises need to employ income strategies and use market methods to solve social problems. Dees and Anderson [5] later refined their "social innovation school" concept, and indicated that social entrepreneurship is about innovation, social impact, value, and goals, not just earning income while doing projects to achieve social missions. 
Over-emphasis on income strategies limits thinking and distracts people from important goals such as the social impact and use of innovative methods to develop resources [5]. Subsequently, Dees and Anderson insist that social enterprises should innovatively integrate corporate and philanthropic methods to create sustainable social values.

Apart from the core content of social entrepreneurship, some scholars have promoted a more comprehensive perspective that reaches beyond social and commercial perspectives at the organizational level. Lundstrom, Zhou, Friedrichs, and Sundin's view of entrepreneurship combined the following three dimensions: social, commercial, and humanistic [6]. The fundamental difference between commercial and social entrepreneurship is that the pursuit and creation of social value - not just selfappropriation value - is the driving force of social entrepreneurship. The humanistic dimension of entrepreneurship is different from the commercial and social dimensions, since it reflects the internal value created by an organization's products and services. It presents the creation of a shared inner value system of an organization which, if displayed, affects public recognition of that organization, and the recruitment of employees [7]. An organization's actions elucidate which values (and related dimensions) it adheres to. However, sometimes there may be a fusion of values and dimensions. Social enterprises' value-creation strategies should display an integrated value system, representative of the three dimensions.

A dynamic, critical, and systematic discussion is needed to understand the dual value and inherent contradictions in the social enterprise and entrepreneurship field. Luhmann categorizes society into temporal, social, and material dimensions [8]. Acceleration prompts society to evolve in the temporal dimension and also changes social and material relationships [9]. Therefore, while discussing "what makes social entrepreneurship entrepreneurship" and "what makes social entrepreneurship social" [10], we should also be cognizant of the effect that modernization has on society. Consequently, we reviewed the various types of alienation inside a social enterprise, especially in its functioning and the changing roles of social entrepreneurs during the process of modernization.

\section{SOCIAL ACCELERATION THEORY}

Rosa highlighted four sociological perspectives relating to modernization described by Weber, Durkheim, Simmel, and Marx - namely culture, social structure, personality type, and relation to nature, respectively [11]. According to Rosa [11] “... modernization is... a process of rationalization, differentiation, individualization, or instrumental domestication..." (p.79) and "we cannot adequately understand the nature and character of modernity and the logic of its structural and cultural development unless we add the temporal perspective to our analysis" (p.79). Rosa postulates that social acceleration [11] "an increase in the decay rates of the reliability of experiences and expectations and by the contraction of the time spans definable as the "present"' (pp. 83-84) — has three dimensions (accelerated technology, social change, and pace of life). These dimensions form a closed, selfpropelling acceleration process or cycle, driven by three primary external factors: economic, structural, and cultural motors.

In terms of social structure, the systemic processing, including economic production and distribution, technological inventions, and artistic productions, has accelerated per their own principles or rules. However, all subsystems are not equally capable of acceleration, thus, causing desynchronization. Rosa also indicates that the social acceleration process has accelerated social change in the basic structure of society (the structure of its associations, groups, and collectives and the corresponding role structures) [11], for example, "family and occupational structures as well as associations and milieus have become highly volatile, shifting, and contingent, making it difficult to identify politically and socially relevant and stale associational structures at all" (p.109), which "further aggregates the problem of social integration for late modern societies" (p.109). In the cultural dimension, the contraction of the present, a "shortening of the time spans within which action orientations and social practices remain stable" (p.109), is the most essential social acceleration effect. The quick changes to practices, lifestyles, and political and occupational commitments make culture in late modern society highly dynamic.

\subsection{Alienation}

Alienation is a central concept in Rosa's theory of social acceleration [9]. Jaeggi [12] defines alienation as "a relation of relationlessness" (pp. 28-30), a deficient relationship with the world. As Nielsen and Skotnicki [13] state, "people interpret their constructed world as wholly given and beyond their control-they feel themselves unable to act meaningfully in the world" (p. 6). Rosa's "alienated world" relationship invokes Jaeggi's concept. He hopes to integrate the meaning of the relationship between the self and the world into the core concept of alienation. Alienation reflects a deep and structural distortion of the relationship between the self and the worldthat is, the way a subject is "situated" in the world has been distorted.

Rosa further indicates that it is not only people's actions - the things they use in labor and life, nature, the social world, and themselves (as Marx said) which alienates them from human beings, but also their time and space [9]. The acceleration of society has created a lot of mobility and disconnection from the physical space, which has also promoted the alienation of our physical or material environment. In modern life, we must use a variety of equipment and tools to complete tasks, but we 
may never truly learn how to understand them. Alienation occurs here because we do not have time to understand what we use and do. When people complain that they cannot do what they truly want to, it is because the "To-do list" in various areas of life is increasing every year. The rhetoric of "must do this" clearly shows the feeling of alienation. Rosa believes that people appear to be willing to do what they do not "truly" want to do [9]. This peculiar form of alienation from our own actions is also a consequence of competition and acceleration. In a world integrated by the order of speed, it is wiser to find a desire that can be satisfied in a short time than to establish a desire that will take a long time to achieve. Rosa marks two specific forms of alienation: temporal alienation and selfalienation. Regarding time alienation, he discusses a general trend of short experience/short memory mode of time experience in late modern society [9]. People are more often involved in exceedingly isolated activities or contexts. For example, people may go to a park, a fitness center, attend a business meeting, go to a supermarket, and so on. All these activities have resulted in isolated actions and experiences that cannot be integrated or meaningfully connected. The time that people experience and the time they spend on the experience are alienated from themselves. People's lack of complete absorption and possession of their own actions and experiences can lead to serious self-alienation and may become an ever-present danger in the late modern acceleration of society [9]. If our identity is formed based upon our standing in the world and the things we care about, but we don't know what is important to us, if we lose the order of important things that are stable and directional, then our self-relationship will suffer and become disturbed.

\section{CASE ANALYSIS}

The author views the case of the SFC as a social entrepreneurial dilemma where alienation occurs at multiple levels. An in-depth analysis may identify the type(s) of alienation and its consequences. Specifically, we will analyze the SFC case regarding: the motivation of the fellows choosing to join the SFC, the model of the SFC, and its critical significance.

Fellows often join the SFC to "make a difference." In this regard, the concept of an acceleration society, proposed by Hartmut Rosa [11], is important. However, "acceleration society" is applied to "a society if and only if technological acceleration and the growing scarcity of time (that is, an acceleration of the pace of life) occur simultaneously, that is, if growth rates outgrow (the) acceleration rates" (p.87). Under these circumstances, people are pressured to keep up with the speed of change in the social and technological world, so that they can maintain competitive opportunities and not lose any potentially valuable options.

However, in a rapidly changing world, it is increasingly difficult to determine which option is more valuable
[11]. Among many complicated choices, joining the SFC to become a fellow seems to reflect a kind of deceleration behavior (fellows leave big cities and live/work in a relatively slow-paced rural life), as a form of deliberate deceleration in Rosa's analysis: the individual's minimized functioning [11]. For example, the fellows seem to slow down in their learning and work process, but it also helps increase the overall amount of learning or the workload of a given time and enhances innovation and creativity [14]. Rosa further concludes that there is an undeniable structural asymmetry between deceleration and acceleration; modernization is a process of social acceleration [9]. In this sense, fellows chose to join the SFC, not to surrender high incomes at big companies or to sacrifice personal advantages to serve poor communities as most media reports suggested; their choices reflected the principles of competition in the acceleration society. It was thus an opportunity to enhance their competitiveness, so that they could return to the accelerated track with an advantage after completing the two-year program.

Additionally, the SFC provided potential future development options for fellows after completing the program. These included opportunities to join well-known domestic investment companies with SFC recommendations; further study at top universities with the founder's recommendation, or long-term partnerships with the cooperatives they helped to establish. Therefore, for many fellows, joining the SFC was a relatively obvious choice. In other words, on the basis of maintaining their competitiveness, they were able to retain the spark of idealism until they found that the spark itself was also feeding the acceleration machine.

Moreover, the time nodes present during the establishment and operation of entrepreneurial projects (oneweek training, one-month research, set-up of cooperatives, and regular assessments), and the close embrace of the SFC and the capital all reflect principles of competitions - the main driving force in an accelerated society. As Rosa indicated, for social actors, acceleration is both a promise and a demand [9] [11]. For example, in the industrial age, people expected acceleration; in the 20th century, acceleration had the potential to liberate. However, during the age of globalization, it has lost its promise, and the pressure to accelerate is so powerful that it consumes everything. Furthermore, the concept of autonomy (both individual and organizational) has become redundant [9]. Creativity, subjectivity, and passion are no longer geared toward taking independent initiative, but toward increasing people's competitiveness [9]. SFC's intervention has directly brought about a phenomenon of "poverty alleviation through consumerism." This phenomenon is also a reflection of the market mechanism, norms, and values that permeate every aspect of human existence by using the market as a means of adjustment in liquid modernity [15] [16].

\section{CONCLUSION}


This article analyzes the conflicts in the SFC, an elite Chinese organization, by using Hartmut Rosa's social acceleration theory. Rosa notes that various modern temporal structures have changed in unique ways and are filled with examples of acceleration. In turn, acceleration is connected to the essence of modernity [9]. Furthermore, Rosa considers alienation as the core concept of Social Acceleration theory [9]. This theoretical framework provides a dynamic and critical perspective of the research on social entrepreneurship and enterprises. Furthermore, it enhances the understanding of its dual value and inherent contradictions.

The author proposes that social enterprises easily overlook humanistic entrepreneurship (a condition for creating harmonious resonance), philanthropic methods (a type of deceleration in reaction to acceleration), and their potential functions in the acceleration society. In the SFC's case, the feelings of helplessness and abandonment, followed by conflicts between the fellows and the management team, reflect the two problems stated by Rosa regarding the mandatory norms that are created by speed, competition, and deadlines in the late modern age [9]. First, these mandatory norms have caused patterns of behaviors and experiences that were not derived from values or desires. Rather, they resulted from continuous alienation of the subject. Second, the late modern context does not offer "mediation" or institution. Therefore, all mistakes and deficiencies are ascribed to the individuals. These two issues present a new form of alienation and should be addressed in critical theory [9].

Concerning poverty alleviation through industry (as a form of social entrepreneurship), some fellows hoped to bring the promise of an accelerating society to poor villagers. However, they also wanted to create their own life stories in an era of "experiencing poverty" as indicated by Benjamin [17] by raising such stern questions about how to establish a responsive relationship between the self and the world.

\section{REFERENCES}

[1] T. Saebi, N. J. Foss, S. Linder, Social Entrepreneurship Research: Past Achievements and

Future Promises. Journal of Management 45 (1) (2019) 70-95. DOI : https://doi.org/10.1177/0149206318793196

[2] M. Zhao, Social Entrepreneurship. China Renmin University Press, 2018

[3] J. G. Dess, The Meaning of Social Entrepreneurship. Centre for Advancement of Social Entrepreneurship (CASE), Fuqua School of Business, Duke University, Durham, 2001. Available at: https://centers.fuqua.duke.edu/case/wp-content/up-
loads/sites/7/2015/03/Article_Dees_MeaningofSocialEntrepreneurship_2001.pdf (accessed 28 January 2011).

[4] J. Boschee, J. McClurg, Towards a Better Understanding of Social Entrepreneurship: Some Important Distinctions, 2003. Available at: http://growingsocial.eu/en/e-library/towards-better-understanding-social-entrepreneurship-some-importantdistinctions (accessed 20 June 2011).

[5] D. J. Gregory, B. B. Anderson, Framing a Theory of Social Entrepreneurship: Building on Two Schools of Practice and Thought. Research on Social Entrepreneurship, (2006) 39-66.

[6] A. Lundstrom, C. Zhou, Friedrichs, Y., E. Sundin, Social Entrepreneurship: Leveraging Economic, Political, and Cultural Dimensions. Berlin, Germany: Springer-Verlag Berlin Heidelberg, 2014.

[7] A. Lundstrom, C. Zhou, Friedrichs, Y., E. Sundin, Social Entrepreneurship: Leveraging Economic, Political, and Cultural Dimensions. Berlin, Germany: Springer-Verlag Berlin Heidelberg, 2014.

[8] N. Luhmann, Social Systems. Redwood City, CA: Stanford University Press, 1996.

[9] H. Rosa, Alienation and Acceleration: Towards a Critical Theory of Late-modern Temporality (vol 3). Aarhus, Denmark: Aarhus Universitetsforlag, 2010.

[10] A. M. Peredo, M. McLean, Social Entrepreneurship: A Critical Review of the Concept. Journal of World Business 41 (2006) 56-65.

[11] H. Rosa, Social acceleration: Ethical and political consequences of a desynchronized high-speed society, in: H. Rosa, W. E. Scheuerman (Eds.), Highspeed Society: Social Acceleration, Power, and Modernity. University Park, PA: Pennsylvania State University Press, 2009, pp. 77-111.

[12] R. Jaeggi, Alienation. Columbia University Press, 2014.

[13] K. Nielsen, T. Skotnicki, Toward a Theory of Alienation: Future Lessness in Financial Capitalism. 2019. Available at https://osf.io/preprints/socarxiv/jkstw/ (accessed 11 November 2020).

[14] L. Sewer, If You Are in a Hurry, Go Slow: New Time Management in an Accelerated World. (Wenn Du es eilig hast, gehe langsam. Das neue Zeitmanagement in einer beschleunigten Welt.). Frankfurt/M., Germany: Campus, 2000.

[15] Z. Bauman, Liquid Modernity, Cambridge, England: Polity Press, 2000. 
[16] M. Davis, Freedom and Consumerism: A Critique of Zygmunt Bauman's Sociology. Aldershot, England: Ashgate, 2008.

[17] W. Benjamin, Experience and poverty, in: M. Bullock, M. Jennings (Eds.), Walter Benjamin: Selected Writings, Volume 2, 1927-1934, Cambridge, MA: Harvard UP, 1999. 